\title{
PUBLIC HEALTH:
}

\section{The Fournal of the Fncorporated Fociety of sildedical Officeris of lbealtb.}

VoL. XVIII. No. 1.

OCTOBER, 1905

\section{OUTBREAK OF SORE THROAT AT COLCHESTER DUE TO INFECTED MILK.*}

\author{
By WILliam G. SAVAGE, B.Se, M.D. (Lond.), D.P.H., \\ Medical Officer of Health, Colchester.
}

DuRING the latter part of April, 1905, an extensive and severe outbreak of septic sore throat occurred.

The outbreak is of interest from a number of points of view, and, I think, worthy of being recorded in some detail. Not being a notifable disease I was only aware that there was any undue prevalence of sore throat on April 25th, and then my knowledge was limited to a quite small number of cases. Certain features of the outbreak, however, made me suspect milk as the cause, and I at once instituted inquiries amongst medical men in the town.

These and other inquiries were pursued with rapidity, so that within two days I was in a position to strongly suspect the cause, while within four days from the outbreak coming to my knowledge it was possible to obtain information which, conclusively to my mind, settled the cause of the outbreak, and to take measures to prevent any fresh cases.

This rapid and satisfactory result was, however, only obtained by the cordial co-operation ot a number of medical men in practice in the town, and the prompt assistance of Dr. Cook, Medical Officer of Health of the Lexden and Winstree Rural District, in which five of the farms were situated.

My information in regard to the place of occurrence of the cases, their milk supply, etc., is derived from three sources.

(a) Information given to me by other medical men.

* Read at Meeting of the Home Counties Branch of the Society of Medical Officers of Health, on July $25 \mathrm{th}, 1905$. 
(b) Personal inquiries, and house to house inquiries in certain streets.

(c) Information as to cases among the military population.

Information supplied to me by medical men.-The information asked for in connection with each affected household was the milk supply, the street in which situated, the number of occupants attacked, and whether males, females, or children. In some cases the dates of onset were also supplied. In all, 85 households were reported to me, and from these 140 cases, in which sore throat attacks had taken place. These figures analysed yielded the following results :-

TABLE I.

\begin{tabular}{l|c|c|c|c}
\multicolumn{1}{c|}{ Milk Supp1y. } & Households. & Cases. & \multicolumn{2}{|c}{ Perentage. } \\
& & Households. & Cases: \\
\hline Mr. M's Milk. & 71 & 123 & $83 \cdot 6$ & $87 \cdot 9$ \\
From other Vendors. & $14^{*}$ & $17^{*}$ & $16 \cdot 4$ & $12 \cdot 1$ \\
\hline
\end{tabular}

The locality of the cases was also supplied to me, and enables me to compare the cases in different parts of the town. Cases in the Barracks, and a small number of cases, the locality of which was not accurately described, are excluded.

The figures are given in Table II.

TABLE II.

\begin{tabular}{|c|c|c|c|c|}
\hline \multirow{2}{*}{ Milk Supply. } & \multicolumn{2}{|c|}{ West side of Town. } & \multicolumn{2}{|c|}{ Rest of the Town. } \\
\hline & $\begin{array}{l}\text { Honseholds } \\
\text { Attacked. }\end{array}$ & $\mid \begin{array}{l}\text { Percentage } \\
\text { (Households) }\end{array}$ & $\begin{array}{l}\text { Fouseholds } \\
\text { Attacked. }\end{array}$ & $\begin{array}{l}\text { Percentage } \\
\text { (Households). }\end{array}$ \\
\hline \multirow{3}{*}{$\begin{array}{l}\text { M's Milk. } \\
\text { From other Vendors. }\end{array}$} & 58 & $96^{\circ} 6$ & 6 & $37 \cdot 5$ \\
\hline & 2 & $3 \cdot 4$ & 10 & $62 \cdot 5$ \\
\hline & 60 & - & 16 & - \\
\hline
\end{tabular}

The area here included as the west side of the town certainly does not include more than 25 per cent of the population of the borough, probably not more than 20 per cent. Yet in this area 60 out of 76 reported cases of sore throat occurred, i.e. 79 per cent of the cases.

We have also the extremely striking fact that $96^{\prime} 6$ per cent of the attacked households in the west side of the town consumed the incriminated milk.

The fact that 83.6 per cent of the households affected had a common milk supply, and that 96.6 per cent of the houses in the west part of

* In only one of these households were there as many as three cases affected and this I subsequently ascertained was also partly supplied with M's milk, but I have refrained from altering, since I wished this table to reflect exactly the information as supplied to me, without any corrections on my part. 
the town had this same supply, points conclusively to that particular milk supply being an etiological factor of importance in the outbreak, unless it so happened that that particular milk vendor supplied about that percentage of the whole town, and of that particular part of the borough.

This, the evidence available quite conclusively disproves, but it will be more conveniently given later on.

Results obtained from house to house enquiries in certain selected areas. -Four areas were selected.

Area 1. Date of inquiry, 27th and 29th April.

In this area four roads were selected which were all upon the same milk round (No. 2), and upon the milk round which the available evidence then showed to be most severely affected. The houses were only of small or moderate size, with a few exceptions, but were inhabited almost entirely by the servant-keeping class.

Some of the results of the enquiry are given in Table III.

TABLE III.

\begin{tabular}{|c|c|c|c|c|c|}
\hline \multirow{2}{*}{ Milk Supply. } & \multirow{2}{*}{ 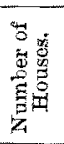 } & \multirow{2}{*}{ 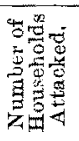 } & \multirow{2}{*}{ 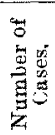 } & \multicolumn{2}{|c|}{ Percentage. } \\
\hline & & & & $\begin{array}{l}\text { Houses } \\
\text { Supplied. }\end{array}$ & $\begin{array}{l}\text { Fouseholds } \\
\text { Attackeã. }\end{array}$ \\
\hline M's Milk entirely. & 35 & 22 & 40 & $58 \cdot 6$ & 63 \\
\hline M's Milk with other supplies. & 5 & 2 & 2 & $8 \cdot 3$ & 40 \\
\hline Milk from other Vendors. & 20 & 0 & 0 & $38 \cdot 3$ & 0 \\
\hline & 60 & 24 & 42 & & \\
\hline
\end{tabular}

Area 2. Date of inquiry, April 27th.

This area comprised all the houses in a road in the centre of the west part of the town. The houses are for the most part considerably larger than those of Area 1. It was selected as being on a milk round (No. 1) in which there had been a number of cases, but less than on Round No. 2.

The chief results of the inquiry are given in Table IV.

TABLE IV.

\begin{tabular}{|c|c|c|c|c|c|}
\hline \multirow{2}{*}{ Milk Supplies, } & \multirow{2}{*}{ 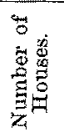 } & \multirow{2}{*}{ 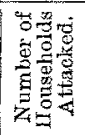 } & \multirow{2}{*}{ 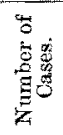 } & \multicolumn{2}{|c|}{ Percentage. } \\
\hline & & & & $\begin{array}{c}\text { Houses } \\
\text { supplied. }\end{array}$ & $\begin{array}{l}\text { Households } \\
\text { Attroked. }\end{array}$ \\
\hline M's Milk entirely & 13 & 5 & 9 & $32 \cdot 5$ & $38 \cdot 5$ \\
\hline M's Milk and others. & 2 & 0 & 0 & $5 \cdot 0$ & 0 \\
\hline \multirow[t]{2}{*}{ Milk from other. Vendors. } & 25 & 0 & 0 & $62 \cdot 5$ & 0 \\
\hline & 40 & 5 & 9 & & \\
\hline
\end{tabular}


Area 3. Date of inquiry, April 28th.

In view of statements made, that the sore throats were not confined to any one locality, but were all over the town, I deemed it advisable to have inquiries made in streets not specially affected. In Area 3 two roads were taken. One, Butt Road, just south of the affected area and roughly parallel to Maldon Road (perhaps the most affected road) and only a few yards from it; and the other Manor Road, just north of the affected area and parallel to Crouch Street, a considerably affected street, and only separated from it by a few yards. Only part of Butt Road was taken. Both streets consist, in the main, of small houses, inhabited for the most part by residents below the servant-keeping class.

The chief results of the inquiry are given in Table $\mathrm{V}$.

TABLE V.

\begin{tabular}{|c|c|c|c|c|c|}
\hline \multirow{2}{*}{ Milik Supply. } & \multirow{2}{*}{ 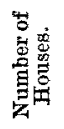 } & \multirow{2}{*}{ 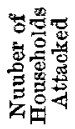 } & \multirow{2}{*}{ 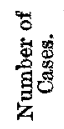 } & \multicolumn{2}{|c|}{ Percentage. } \\
\hline & & & & $\begin{array}{c}\text { Houses } \\
\text { Supplied. }\end{array}$ & $\begin{array}{l}\text { Households } \\
\text { Attacked. }\end{array}$ \\
\hline M's Milk entirely. & 7 & 2 & 4 & $7 * 6$ & 29 \\
\hline M's Milk and others. & 2 & $\overline{1}$ & 3 & $2 \cdot 2$ & 50 \\
\hline \multirow{2}{*}{ Milk from other Vendors. } & 83 & 5 & 5 & $90 \cdot 2$ & 6 \\
\hline & 92 & 8 & 12 & - & - \\
\hline
\end{tabular}

Area 4. Date of inquiry, April 27th, 1905.

This comprised a long road-Canterbury Road-remote from the affected part of the town, being in the South Ward, and to which very little of the suspected milk was being sent. This road was selected as one in an area in which sore throats had been previously rather prevalent, and which had been the seat of the majority of the more recent cases of diphtheria. The houses were small, and the occupants were below the servant-keeping class. I wished to ascertain if sore throats were equally prevalent in this district, since it had been stated that the cases were all over the town.

The chief results of the inquiry are given in Table VI.

TABLE VI.

\begin{tabular}{|c|c|c|c|c|c|}
\hline \multirow{2}{*}{ Milk Supply. } & \multirow{2}{*}{$\begin{array}{l}\text { Number of } \\
\text { houses. }\end{array}$} & \multirow{2}{*}{$\begin{array}{l}\text { Number of } \\
\text { households } \\
\text { attacked. }\end{array}$} & \multirow{2}{*}{$\begin{array}{l}\text { Number of } \\
\text { cases. }\end{array}$} & \multicolumn{2}{|c|}{ Percentage. } \\
\hline & & & & $\begin{array}{l}\text { Honses } \\
\text { supplied. }\end{array}$ & $\begin{array}{l}\text { Households } \\
\text { attacked. }\end{array}$ \\
\hline $\begin{array}{l}\text { M's milk entirely ... } \\
\text { M's milk and others } \\
\text { Milk from other vendors... }\end{array}$ & $\begin{array}{r}2 \\
0 \\
89\end{array}$ & $\begin{array}{l}0 \\
0 \\
8\end{array}$ & $\begin{array}{l}0 \\
0 \\
8\end{array}$ & $\begin{array}{c}2.2 \\
0 \\
978\end{array}$ & $\begin{array}{l}0 \\
0 \\
9\end{array}$ \\
\hline & 91 & 8 & 8 & - & - \\
\hline
\end{tabular}


The figures as a whole may be first considered, and for clearness are restated in the following table:-

TABLE VII.

\begin{tabular}{|c|c|c|c|c|c|c|}
\hline & & $\begin{array}{c}\text { Area } \\
\text { I. }\end{array}$ & Area & $\begin{array}{l}\text { Area } \\
\text { III. }\end{array}$ & $\begin{array}{l}\text { Area } \\
\text { IV. }\end{array}$ & Totals. \\
\hline Number of houses & & 60 & 40 & 92 & 91 & 283 \\
\hline Houses supplied with M's milk $\quad \ldots \quad \ldots$ & & 35 & 13 & 7 & 2 & 57 \\
\hline " " " py " " and other sources & & 5 & 2 & 2 & 0 & 9 \\
\hline $\begin{array}{ll}\text { Household" attacked, supplied by } \text { y. }^{\prime} & \ldots \\
\end{array}$ & ... & $\begin{array}{l}20 \\
22\end{array}$ & $\begin{array}{r}25 \\
5\end{array}$ & $\begin{array}{r}83 \\
2\end{array}$ & $\begin{array}{r}89 \\
0\end{array}$ & $\begin{array}{r}217 \\
29\end{array}$ \\
\hline Households attacked supplied by other vendors & & $\begin{array}{l}2 \\
0\end{array}$ & $\begin{array}{l}0 \\
0\end{array}$ & 1 & $\stackrel{0}{8}$ & $\begin{array}{r}3 \\
13\end{array}$ \\
\hline
\end{tabular}

This table very clearly brings out the following facts :-

1. That sore throats were by no means prevalent all over the town, but were distinctly localized in their prevalence.

2. That although only 57 of the houses were supplied by M.'s milk alone, yet of these, 29 households were affected with sore throat; a percentage of 50.9 .

The houses supplied by other vendors, as well as M.'s milk, gave a percentage of $33: 3$ of households affected.

3. Although 217, or over three-fourths, of the houses were supplied by other vendors, yet there were only 13 sore throat households among these; a percentage of 5.99 .

In round figures, half the households supplied by M.'s milk alone were stricken with sore throat, one-third of those partly supplied, and only one-seventeenth of those supplied from other sources.

If cases are considered and not households, the figures are even more striking.

In the 57 houses supplied by M.'s milk alone there were 53 cases of sore throat. In the 217 houses supplied by other vendors there were 13 cases of sore throat.

That there were 13 cases of sore throat in houses not supplied by the incriminated milk does not, of course, in the least invalidate the evidence as to infectivity of M.'s milk. For, in the first place, many of the cases occurred during Easter time, when intercommunication between houses would be extensive, and possibly infective milk consumed in this way. Also, when the number of inhabitants concerned is considered, 13 cases of sore throat within a period of two weeks is by no means above what is reasonable to expect under perfectly normal conditions, particularly as the great majority of them were not severe enough to require the services of a doctor. In these 217 houses there were 941 people, so 13 cases is by no means an 
excessive number of cases. The 13 cases were supplied from eight different milk supplies.

The connection of M.'s milk with the outbreak seems from these figures to be quite conclusively demonstrated. They, however, are capable of further information.

From Mr. M. I ascertained that he has five milk-rounds, which are in the main fixed, although the milk sent upon these rounds is subject to considerable variability.

The figures in the above tables show that Area 1 was particularly affected, Area 2 to a less extent, and Area 3 to a still less extent.

Area 1 as regards M.'s milk, is entirely on milk-round II, Area 2 on milk-round I, while Area 3 is largely on round IV.

This was also demonstrated by the cases supplied to me by medical men, for 30 households were upon milk-round II, 12 upon round I, 7 upon round III, 5 were upon round IV, and the remaining 17 could not be located with certainty, although at least half were upon round II. The maximum incidence was mainly upon milk-round II, but also considerably affected the other milk-rounds. Mr. M. informed me that the milk from farm $A$ always went on round I (although it was not enough to completely supply it), and the milk from farm B generally upon round II, but by no means invariably, while the milk supplied to the other rounds was most variable. On the results of the distribution of the cases alone, milk from farm B seemed to be the most likely cause of the epidemic.

The military figures are best considered by themselves.

Sore throats were especially prevalent in the Barracks and Camp during the second half of April. For the officers I have not been able to obtain reliable figures, so I have excluded them from consideration. For the other military statistics which follow, I am indebted to the kindness of Colonel Robinson and Major Freeman, who have taken every trouble to ensure their accuracy.

The men are quartered in two separate places, the Camp and the Barracks, separated by a wide common, the so-called Abbey Field. Both Camp and Barracks are supplied by M.'s milk, but they are upon two separate milk-rounds.

During the month of April 60 cases of sore throat, including tonsillitis, were admitted to the military hospital (men only).

From April 1st to 16th 6 men were so admitted.

$"$, 16th to 30 th $54, ", "$,

The difference is marked, and shows that the military quarters were considerably affected. There were probably also a large number of slight cases not admitted to hospital.

The number and distribution of the cases severe enough to be admitted to hospital, were as follows :-- 
TABLE VIII.

\begin{tabular}{|c|c|c|c|c|c|}
\hline \multicolumn{3}{|c|}{ Military Quarter. } & \multirow{2}{*}{$\left|\begin{array}{c}\text { Average number } \\
\text { of men. } \\
2442 \\
1311\end{array}\right|$} & \multirow{2}{*}{\begin{tabular}{|c|}
$\begin{array}{c}\text { Sore throat cases } \\
\text { (April). }\end{array}$ \\
46
\end{tabular}} & \multirow{2}{*}{\begin{tabular}{|c} 
Attank incidence \\
per 10c0 mex.
\end{tabular}} \\
\hline $\begin{array}{l}\text { Barracks ... } \\
\text { Camp } \quad \ldots\end{array}$ & $\begin{array}{l}\cdots \\
\cdots\end{array}$ & $\begin{array}{l}\ldots . \\
\ldots\end{array}$ & & & \\
\hline \multicolumn{2}{|c|}{ Totals } & $\ldots$ & 3758 & 50 & $15 \cdot 9$ \\
\hline
\end{tabular}

Table VIII shows that there was a difference of incidence between those in Camp and those in Barracks, nearly twice as many men being attacked in Barracks as in the Camp.

At the military hospital, however, the milk supply was not from M. but from a quite different vendor. Colonel Robinson informs me that amongst this portion of the military community ther was not a single case of sore throat. The following are the actual figures:-

\begin{tabular}{|c|c|c|}
\hline Military Hospital. & Number. & $\begin{array}{l}\text { Cases of } \\
\text { sore throat. }\end{array}$ \\
\hline 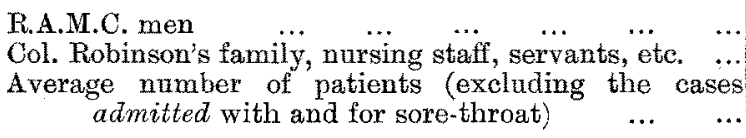 & $\begin{array}{r}52 \\
21 \\
147\end{array}$ & $\begin{array}{l}0 \\
0\end{array}$ \\
\hline Total & 220 & 0 \\
\hline
\end{tabular}

In position the Hospital stands between the Camp and the Barracks, but these 220 people quite escaped, although many of them were engaged in nursing these sore-throat cases.

In regard to the women and children of the military quarters my figures are less complete, but there were apparently at least 14 cases of sore throat during April among an average number of women and children of about 680 , giving an incidence of 20.5 per 1,000 cases.

These figures show that the military quarters were affected, but to a much less degree than certain other parts of the town.

To complete the proof that the incidence was excessirely upon M.'s supply, it only remains to consider his share of the town milk supply, and whether it is possible that the incidence was so largely on his supply, because he supplied approximately that proportion of the population.

In the first place, the house to house inquiries quite exclude such a supposition.

In the second place, the previous year I had personally inspected every cowshed in the Borough on the register, and had an accurate record kept of all particulars. Assuming that the number was the 
same as for the previous summer, and excluding those supplying milk to M., there would be 363 cows furnishing milk to the town. From my knowledge of the milk supply I can say that, putting it at a very low figure, the milk from 130 cows at least from outside is consumed in the Borough. If we take 127 this gives 490 cows. M. was at the time of the outbreak receiving milk from exactly 100 cows. Therefore, his share could only be $\frac{100}{5} 30$, or 17 per cent. M.'s milk in the main supplies the larger houses, which proportionately consume double or treble that of the smaller houses, so that his share of the town's supply is probably much below 17 per cent. From a knowledge of the actual number of houses supplied by $M$. it is a quite safe assumption that the number of persons supplied by him, excluding the military, is less than 10 per cent of the civilian population.

The milk supply implicated was very carefully inquired into. The milk purveyor, Mr. M., was visited by me on April 26th, and his premises inspeeted, and full inquiries made as to the source and distribution of his milk. The amount sold daily by him is several hundred gallons. No cows are now kept on the premises, and at the time of the outbreak he was acting entirely as a purveyor of milk obtained from a number of different farms. The premises were clean and well kept, and were supplied with town water. I had on previous occasions visited these premises, and had always found them clean and well kept.

The milk was derived from six farms, which I will call A, B, C, D, E and F. Farm B is within the Borough, which is very extensive, and includes about 30 farms with cowsheds within its area. (Area of the Borough is 11,324 acres.) The other five farms were in a neighbouring rural district. The milk from the five farms outside the Borough is during the winter and was at the time of the outbreak only sent to Mr. M. once daily; that is every morning, the afternoon milk being cooled on the premises, and kept to be sent with the morning milk of next day. These five milks are all said to be cooled before they are sent to $\mathrm{Mr}$. M.

The milk from farmer $B$ is sent twice a day, and in an uncooled condition to the purveyor, who informed me that he cooled it himself on his premises. He also informed me that sometimes, owing to the milk being late, etc, the other supplies were sent to him uncooled, and were cooled by him.

From Mr. M.'s premises the milk is sent on five separate milk-rounds. While the milk-rounds are definite, or almost so, the milk sent on these rounds is very variable. As already mentioned, the milk from farm A always went on round $I$, which supplied the best part of the tnum and mille from farm $B$ conarally on romed TT. For the other 
three rounds the milk used was very variable. A dairy of Mr. M.'s in one of the streets in the west part of the town was also supplied from farms A and B.

The military supply is partly on round III, and the rest on round $\mathrm{V}$. Inquiries as to illness at the depôt, or among the employés, elicited the following facts : Mr. M. himself had had a sore throat and other symptoms, which convinced me that he had had a typical attack. The sore throat started April 20th; he was oonfined to bed on April 21st for one day or longer, and was better in a few days' time. His wife and children, he told me, remained well.

In regard to his drivers, Mr.M. admitted that the drivers of the milk carts for both round II and round III had had attacks of sore throat, while the wife of the driver on round I had been attacked, but not the milkman himself.

Also in the dairy referred to above, there were four cases of typical sore throat attacks (three adult females and one child).

The information available even at as early a date as April 27th showed that the main brunt of the outbreak had fallen upon houses supplied by round II, while also, but to a distinctly lesser degree, houses were implicated on round $\mathrm{I}$ and in the military areas.

Although, however, farm B was most suspected, I deemed it necessary to inspect all the farms supplying milk to Mr. M., farm B being, however, first investigated.

In the afternoon of April 27th farm B was visited by me, accompanied by Mr. Taylor, Veterinary Surgeon, and Veterinary Inspector for the Borough. We visited without warning, and at the time when the cows were just being milked for the afternoon milk.

The farm, as already mentioned, is in the Borough, but was unregistered. I was quite unaware that milk for sale was distributed from this farm, and the farmer's excuse was, that he had no idea that he had to be on the register before he could sell his milk.

The five cowsheds were on the whole satisfactory, but one was overcrowded, while the cows were fairly clean. The milk vessels were washed with the town water, a supply of which was laid on.

The Veterinary Surgeon examined each cow separately, and, at my request, milked some of the milk from each quarter of each cow. Of the $20 \mathrm{cows}, 19$ gave milk to the naked eye quite normal. The remaining cow had a distinctly diseased udder. Two quarters gave apparently healthy milk, the milk from one quarter was slightly discoloured and suspicious, while that from the remaining quarter was yellow brown, and apparently thin pus. The farmer then stated that this cow's udder had been like this for about a week, but that when it was noticed, about April 19th, the milk from the affected quarter 
was not mixed with the milk, but was milked on to the ground. He, however, admitted that the milk from the other three quarters was being added to the milk. The cow was in the middle of a shed containing seven cows, and was not in any way marked off from them.

Very detailed inquiries were then made, and also on su subsequent visit, as to any illness among those living or working on the farm, and as to recent changes.

Mr. B. informed me that there had been no additions or alterations during the past six weeks or more in the number of the cows, or in regard to those working upon the farm.

A number of people had, however, been recently suffering from sore throat on the farm.

Mr. B. himself had been ill with influenza and sore throat. His illness dated from April 17th, and he was in bed for 3-4 days, and it was evidently a severe attack. His medical attendant, whom, with $\mathrm{Mr}$. B.'s permission, I consulted for details, informed me that he had a well marked sore throat, the throat being red and swollen.

His eldest son, who is one of the milkers, had a typical attack of sore throat, which started April 21st, and confined him to bed for several days. Mrs. B. and several of the younger children also had sore throat attacks, but mild in character. Two or three of the children were apparently unaffected.

Of particular interest is the fact that the eldest daughter of $\mathrm{Mr}$. B. (age 22-23) came home for a visit from a neighbouring town many miles away, on April 23rd, and developed an attack of "influenza" and sore throat on April 25th, so that she could not return for some days.

The rest of the personnel of the farm had not been affected as far as the inquiries could ascertain, and except the above no one had been ill for many months. The only exception to this was the fact that a boy on the farm, who assisted in the milking, had had a bad cold, etc., two months previously, and had had to attend a doctor. Inquiries of his doctor as to the facts of this case showed his illness had been mild, and was due to a cause quite unconnected with sore throat, or indeed any septic process in any way.

The milk sent from this farm to Mr. M. was about 30 gallons per day, and Mr. B. told me that all of it, except the little used by his family alone, was sent to Mr. M.

All the other five farms were inspected next day. They were all in the Lexden and Winstree Rural District. Of these farms, A, C, and D were inspected by Dr. Cook (the Medical Officer of that District) and myself, and farms E and F by Dr. Cook alone, who, however, kindly supplied me with full particulars. 
It is not necessary to enter into detail of these, except to say that, although we examined every udder and every teat separately, in no case did we find a cow giving milk which looked to be otherwise than normal. Farm A, one to which a little suspicion attached from the etiological inquiries, proved to be particularly well kept, and the cowsheds excellent.

In regard, however, to Farm F, Dr. Cook informed me that, although he found no diseased cow, yet the cows were in a very dirty and filthy condition, and the premises totally unsuited for the purpose. The milk on this farm was supplied from 17 cows.

Inquiries were also made as to any illness among the men employed, or at the farm. On none of these five farms had there been any illness for a long period.

On farm A the number of cows was 25. Nearly all the milk was sent once a day to Mr. M., after first being cooled on the premises, but, in addition, eight families in the immediate neighbourhood of the farm were supplied by the milk. In no case was any history of sore throat or other illness among these families obtained.

In the same way, from farm $D$, with 18 cows, several families in the immediate neighbourhood also received the milk, but had had no sore throat or illness.

The examination of these six sources of supply implicates, with certainty, tarm B, and apparently farm B alone.

Apart from the diseased cow, the number of cases of sore throat in connection with this farm is sufficient to indicate it as the sonrce of the trouble.

The important question then arises, had the outbreak a bovine or a human origin?

The first illness on that farm was of Mr. B. himself. This began on April 17th. Mr. B. said he has but little to do, personally, with the cows, and never milked them. From inquiries made, and from information supplied to me by medical men, it is undoubted that a number of cases of sore throat were observed on April 17th, 18th, etc., although the maximum incidence fell on April 20th-22nd. It seems, therefore, most unlikely that Mr. B. himself could have started the outbreak. He was a victim, not the originator. Very careful and repeated inquiry elicited no other illness, so that, even apart from bacteriological grounds, the only possible cause of the outbreak appears to be the diseased cow found on my first visit.

The explanation of the outbreak I take to be the following. The cow in question developed mastitis in one or more quarters. At first this was unnoticed, the milk, although largely loaded with virulent streptococi, being to the naked eye unaltered, or not sufficiently 
altered to be noticed by the ordinary milker. In this way virulent streptococei obtained access to the milk. About April 19th the disease in this quarter at least was so pronounced that it was obvious, and the milk from that particular quarter was rejected.

If this date is accurate, and the incubation period is two days, as on other ground I surmise, the maximum infection of the millk would be about April 19th, and the maximum number of cases about April 21st and 22nd, which appears to be the case.

After the detection on April 19th, the infection of the milk would be less, for although the secretion from this quarter was rejected (if we allow ourselves to accept this statement as accurate), yet the other quarters were milked into the pail, and it seems only too likely that, especially in the early morning hours, the particular infected quarter would not be kept in mind by the milker, and its existence only remembered when the abnormal fluid was seen pouring into the pail. In this way it seems to me as practically certain, that some of the milk from the affected quarter was being added to the milk daily, right up to the time of inspection, and this more particularly since the farmer made light of the condition. This supposition fits in with the time distribution of the cases.

The cessation of the outbreak corresponded with the exclusion of the milk of this particular cow.

The distribution of the cases does not in the slightest negative the supposition that the milk from farm B was the only cause of the outbreak. The milk from farm B went mainly, but by no means exclusively, on round II. The incidence was mainly, but by no means exclusively, upon round II. Thus area 1 of the house to house inspection is entirely on round II, and the percentage of sore throat houses supplied by Mr. M. alone was 63, while area 2 is on round 1, and the percentage of sore throat houses supplied by Mr. M. alone was 38.5. This is even more obvious when the number of cases and not households is considered, as can be seen by consulting these tables.

So far I have mainly concerned myself with the proofs that the outbreak was due to infected matter transmitted by a particular milk supply, but now will consider briefly a number of other facts about the outbreak.

In the first place as to the number of cases. Not being a notifiable disease this can only be estimated approximately. Certain available figures, however, offer a basis for estimation. Thus, among the men of the garrison, during the second half of April, the sore throat cases admitted to hospital were 54 , and only 6 for the first half. The difference, 48 , may fairly, therefore, be assumed to be due to the infected milk. 
Also 123 cases were reported to me by medical men. These were only the cases reported by certain medical men, and for some of them, only their earlier cases. I think it highly probable that there were at the very least 30 cases among the other medical men, or later unreported cases.

In the house to house inquiry made, of the 32 households affected and 58 cases, only 7 households and 13 cases were being attended by medical men, i.e. practically 22 per cent for both.

Probably, therefore, to say that only 25 per cent of those attacked were attended by medical men is rather under than overstating the case. If, therefore, there were $153(123+30)$ cases attended by medical men, there were in all probability $153 \times 3$, or 459 , not so treated. These figures give a total of 660 . While admitting that these figures have no claim to precise accuracy, I think that they at least demonstrate that the outbreak was very extensive. No deaths were traceable to the sore throat infection.

The clinical symptoms, as might be anticipated, varied to some extent, but the majority of the cases had a considerable similarity.

The onset was usually rapid, with considerable constitutional disturbance and temperature; occasionally vomiting, and not infrequently limb pains. In some cases the temperature was very high, up to $104^{\circ}$ or $105^{\circ} \mathrm{F}$. in several instances.

The throat was always red and swollen, and in most cases the tonsils were enlarged, with projecting white plugs in the follicles. These were at first discrete, but in not a few cases they ran together, and formed a distinct slough, simulating diphtheritic membrane. In several cases distinct patches were observed on the soft palate, and in one case on the uvula also, making a diagnosis from diphtheria impossible without bacteriological investigation. The submaxillary glands were generally enlarged and painful. In no case was any rash observed, and, as far as I know, no medical man had any difficulty in its diagnosis from scarlet fever.

The symptoms were evidently those of "septic sore throat," and rapidly yielded to treatment, although in several instances they progressed to quinsy. The only diseases from which a diagnosis had in any way to be made were influenza and diphtheria. Bacteriology excluded the latter in the few doubtful cases; and the prominence of the throat lesions were in themselves sufficient to explain the constitutional disturbance and to exclude influenza, while there was no evidence at all that influenza was present in the town.

Another point of interest is, to what extent was the epidemic spread by secondary cases, due to direct infection from case to case?

We may take it, I think, for granted, that a disease due presumably 
to a streptococcus, and capable of being given off from the buccal discharges, is infectious in a localized way, and capable of originating secondary cases. The information available, however, points to the probability that the great majority of the cases were primary, and but few secondary. Studying the dates of origin in individual houses I find great variety, for in many households all or nearly all those affected were attacked the same day, while in others they followed one another at irregular intervals.

From information supplied to me by medical men, I gather that there were practically no fresh cases after April 29th. If secondary infection played any considerable part, I should have anticipated a much more gradual cessation. It is also of great significance that, although as many as 54 soldiers were admitted to the military hospital with sore throat between April 16th and 30th, yet Colonel Robinson, the Medical Superintendent, informs me that in no case was there any sore throat among nursing staff or R.A.M.C. men.

In one interesting instance, kindly furnished to me by Dr. Chichester, the only person attacked was a lady who used to go to the town depôt, kept and supplied by the milkman M., and drink there daily a glass of his raw milk. The rest of the family had a different milk supply, and all escaped. Less complete but somewhat similar instances have been given me, and in all of these there were no secondary cases.

Of the same class of evidence is the fact that, in quite a number of instances, numbers of the adults, particularly the female servants, including nurses and nursemaids, were attacked, but invariably the children who received only boiled milk escaped. If secondary infection was extensive, probably these children would not have escaped so universally. A typical instance, which I personally observed, is the following: In one family, the lady of the house, who drank a glass of raw milk daily for lunch, was first attacked; subsequently both the maid-servants, one of them being the nurse, were attacked, both of whom drank raw milk; while the head of the house, who only drank milk in tea, escaped, as did also the two children $(8$ months and 4 years) receiving all their milk boiled; and this in spite of the fact that the nurse, whose throat was typical, but not severe, continued to look after them.

The duration of the outbreak.-.-It apparently started about April 17 th, ceasing about April 29th. For only a small proportion of the cases supplied to me by medical men were the precise dates of onset given, but as far as they were received they substantiate the dates of onset supplied to me in the house to house inquiries made. The dates of onset of the 57 cases met with supplied by M.'s milk were 
stated to be as follows: April 15th, 1 case ; April 16th, 1 case ; April 17th, 2 cases; April 18th, 2 cases; April 19th, 3 cases; April 20th, 7 cases; April 21st, 12 cases; April 22nd, 15 cases; April 23rd, 4 cases ; April 24th, 1 case ; April 25th, 5 cases; April 26th, 2 cases ; April 27 th, 2 cases. Cases which developed later would not, of course, be included.

From these figures, and also from the cases supplied to me by medical men, it appears that the great brunt of the outbreak was on April 20th to 25th.

The incubation period.-I have no precise data enabling me to fix this with accuracy, but the following cases, at least, suggest that it was not longer than two days.

(a) Miss B. came home from Sudbury April 23rd, to a house consuming the incriminated milk, and where there were several other cases. April 25th, she developed an attack with typical sore throat symptoms.

(b) An adult male came from London, April 20th, to Colchester. He was taken ill April 22nd, i.e. within 48 hours after coming to Colchester, with typical sore throat symptoms. He drank M.'s milk.

The age and sex incidence.- - Of the cases supplied to me by medical men, in only 74 is the sex, and whether child or adult, supplied to me. These 74 cases were as follows : Adult males, 13 ; adult females, 43 ; children, 18. That is, females suffered about $3 \frac{1}{2}$ times as much as males, and adults furnished 3 times as many cases as children.

Of the 57 cases ascertained on the house-to-house inquiry, 9 were adult males, 40 adult females, 7 children, and one not stated.

This higher incidence upon females is one of the characteristics of milk-borne infection.

That the number of children attacked was not larger, is probably to be explained by the fact that the outbreak mainly attacked those of good social position, and, in a great many instances, the milk was boiled for the children.

The results of the bacteriological investigations.-These were of two kinds: The examination of swabs from typical cases of sore throat, and examination of milk samples.

Swabs from typical cases.-About 12-14 such swabs were examined. They all showed streptococei, with or without staphylococci. From none of them were diphtheria bacilli demonstrated in the blood serum cultures, and in no case were yeasts of any kind found.

In 5 cases the streptococci were isolated, and their character studied in pure culture. Most of them showed several kinds of streptococci in the same swab, and 8 streptococci strains were isolated and studied.

There were two main groups, members of each being isolated in each case from 3 different throats. 
In the one group, the streptococci produced a distinct deposit in broth, but the broth above remained clear. No marked coherency of the deposit. On blood serum they grew as minute white colonies. They produced acid in milk, and rapidly coagulated it. In broth or agar condensation fluid (method of examination recommended by Mervyn Gordon) they showed no lacework or conglomeration of the cocci, and in all the chains were short or of medium length. Both groups stained well by Gram's method.

The other group differed mainly in that they produced turbidity of the broth with abundant deposit, which was partly coherent. No lacework or conglomeration in broth or agar condensation fluid. Acid and milk coagulation like the first group. The chains in this group were very long.

Both groups were tested upon mice, subcutaneous injections of 0.5 cc. broth culture being employed, but in both cases without obvious ill-effects.

The remaining two organisms failed to coagulate milk.

Pressure of other work prevented more detailed bacteriological investigation; and these results cannot be taken as demonstrating any one kind of streptococcus as the proved etiological cause of the outbreak, although from the constant presence of streptococei in the throats, and the apparent absence in some cases of all other organisms, it seems justifiable to assume that these sore throats were due to streptococcal infection.

Turning to the examination of milk samples, in all 8 mixed milk samples were examined.

Two of these were samples taken April 25th and April 26th from a house with three typical cases, on milk-round II, and so probably supplied with milk from farm B. In both of them the centrifugalized deposit of $20 \mathrm{cc}$. showed leucocytes to be extremely numerous, and long chains of streptococci were found. The leucocytes were numerous enough to state that the sample contained pus.

The other 6 samples were samples of mixed milk from each of the 6 farms, and taken at the time of infection. The deposits of all 8 samples were prepared in the same way by centrifugalizing $20 \mathrm{cc}$. in a machine running 1,500 to 1,800 times (electrically driven) for one hour, so that they were comparable. Two platinum loopfuls of deposit spread over a coverglass for a preparation, and stained by methylene blue. All 6 samples gave a deposit which showed a considerable number of leucocytes, but not in numbers sufficient to constitute pus, while in none of them were streptococci chains found.

In all 8 samples streptococci were present in at least $\frac{1}{10} \mathrm{cc}$. of the milk as received, that is, when this quantity of the milk was added 
to broth tubes and incubated for two days, hanging-drop preparations readily showed streptococci.

In all but one sample the streptococei, in most cases several kinds, were isolated from these broth tubes, and their characters studied. There were a number of different kinds, but no facts of interest to the present enquiry were obtained. The virulence of only one was tested by subcutaneous inoculation into a mouse. It was non-pathogenic.

In regard to the diseased cow from farm $\mathrm{B}$, the microscopic examination of the fluid from the markedly diseased quarter showed the deposit to consist entirely of pus cells, mucous threads, and numerous streptococci, mostly of medium length. The centrifugalized deposit from the suspected quarter of the same animal showed very numerous leucocytes, and a few streptococci chains. Evidently pus, but a markedly less advanced condition as compared with the other quarter. The streptococeus isolated from the markedly diseased quarter grew in broth with a slight deposit, but the fluid above remain clear. The deposit showed long streptococci, many very long, no marked twisting, and no conglomeration of chains. In litmus milk it produced acid, and microscopically showed very long streptococci chains. 0.5 cc. of a 24 hours' old growth in milk injected subcutaneously into a mouse produced no ill-effects. Unfortunately it rapidly died out, so I was unable to ascertain its other characters.

These results can only be taken as showing that the pathological condition of the cow was an inflammatory one, and due to a streptococcal infection; that this infection was causing a marked mastitis in one quarter, the secretion being thin pus loaded with streptococci, while a much less marked but similar condition was present in an adjoining quarter.

They further show that the mixed milk samples presumably (but not with absolute certainty) derived from this farm, and obtained one or two days before the detection of the diseased cow, contained pus and streptococoi numerous enough to be detected by direct microscopic examination of the deposit, while later samples from all 6 farms contained no pus.

Personally, I have no doubt in my own mind that this infective mastitis was the cause of the trouble, the etiological cause being a virulent streptococcus in the udder secretion.

It may be raised as objections that the streptococcus isolated was not pathogenic to a mouse, while also that mammitis conditions are fairly common, yet as far as we know in very many cases do not render the milk harmful.

In regard to the first point, it is not a reliable deduction to say 
that a streptococcus which, when injected into a mouse, does not kill the animal, is therefore incapable of causing disease in human beings. All workers who have experience in testing and working at the virulence of streptococci will bear this out. It is a no more reliable deduction than to say, that because a $B$. coli will kill a guinea-pig on intraperitoneal injection, therefore that organism is pathogenic to man. The inoculation test is of importance from other points of view. The only certain test in this direction is to ascertain if this infected fluid could set up sore throat when applied to the throats of human beings; but no one volunteered.

In regard to the other point, I believe that there are different kinds of mastitis in cows. There are certainly many different linds of streptococci, and it is highly probable that what is included under the name of mastitis includes conditions set up by streptococci, or other bacteria, of different kinds, although clinically, or even bacteriologically, the differentiation is a difficult one. Clinical bacteriology can give illustrations in abundance.

At present, as far as I am aware, no one is able to say whether any given case of cow mastitis is a condition capable of affecting milk so as to render it a cause of sore throat, or whether it is comparatively harmless. The practical bearings of this question are obvious.

Having stated as clearly as possible my belief that these streptococci from this particular cow were the cause of the outbreak. I would yet freely admit that the one final link in the chain, the actual proof that the streptococci in the fluid from the diseased udder were the same as the streptococci which were the cause of the sore throats, is not forthcoming. I am constrained to emphasize this because, as a bacteriologist reading the published accounts of milk-borne sore throat outbreaks, I have been struck with the quite inadequate bacteriological grounds on which, in the majority of outbreaks, streptococci found in a certain cow's milk have been stated to be the actual cause of the outbreak, generally merely on the ground that streptococei (as a class) were also found in throat swabs.

To find that in the peccant, or at least suspected milk, there are streptococci, and to also find streptococei in the throats of the cases, these facts by themselves do not prove any etiological connection; indeed, they prove nothing. Streptococei are invariably present in the human throat, while it is less certainly recognized, but equally true, that streptococei are very frequently present in cows' milk, in milk, which, as far as we know, is quite harmless. The precise significance of such streptococci has yet to be determined.

Dr. Bergey* has made some careful and valuable investigations

* Bulletin No. 125, Department of Agriculture, Pennsylvania, U.S.A. 
into this question, and his results show that streptococci are by no mears infrequently present in cows' milk.

The relationship of streptococci to leucocytes, and of both to inflammatory conditions of the cow's udder, is one of great interest, but I cannot discuss the matter within the limits of this paper.

In regard to streptococci in milk, the following investigation may be mentioned in illustration of my contention.

I recently examined the milk of seventeen individual cows. After the first portions of milk were rejected the milk was milked direct into a sterile bottle, each bottle containing the mixed milk from the four quarters of one cow. The cows were all apparently healthy and in good condition, and were in some of the best constructed and kept cowsheds in the Borough.

The milk was examined within half to one hour of the millking. Streptococci were absent in all in $0.1 \mathrm{cc}$. of milk, but in five out of the seventeen were present in $1 \mathrm{cc}$. In the centrifugalized deposit of $10 \mathrm{cc}$. microscopic preparations failed to demonstrate them.

In other words, in apparently healthy cows, and giving apparently normal milk, in 30 per cent streptococi were present in as little as $1 \mathrm{cc}$. of the milk.

In the diseased cow, the condition present was a very different one, since it was obvious that the cow was suffering from a pathological condition of a severe kind, and due to a streptococcus; and taking into consideration all the evidence it is almost certain that this streptococcus caused the outbreak: still, on purely bacteriological grounds, this proof is not forthcoming.

It is a matter of extreme difficulty to actually supply this final proof, so that I cannot regard my failure on this point as in the slightest invalidating the accumulated evidence, when every point of view is considered, connecting this diseased condition with the outbreak.

In conclusion, and summing up the outbreak, I would submit that the proof of the implication of this purveyor's milk is complete; that the evidence involving the particular farm is irresistible; and that the conclusion that this particular cow was the cause, although not absolutely unassailable, is yet extremely strong, the one unproved link being a demonstration that the particular streptococcus found was identical with the streptococci causing the outbreak, a matter of extreme difficulty to prove.

Control of the Mrek Supply.--The Milk Commission of the Medical Society of the County of New York has sent out a notice to the effect that, while it has supervision only of that portion of a dealer's milk which carries certification, it does not intend to allow a dealer known to have adulterated milk to sell certified milk. 